Article

\title{
Large Inverse Magnetocaloric Effects and Giant Magnetoresistance in Ni-Mn-Cr-Sn Heusler Alloys
}

\author{
Sudip Pandey ${ }^{1, *}$, Abdiel Quetz ${ }^{1}$, Anil Aryal ${ }^{1}$, Igor Dubenko ${ }^{1}$, Dipanjan Mazumdar ${ }^{1}$, \\ Shane Stadler ${ }^{2}$ and Naushad Ali ${ }^{1}$ \\ 1 Department of Physics, Southern Illinois University, Carbondale, IL 62901, USA; \\ anorve2002@yahoo.com (A.Q.); aryalanil@siu.edu (A.A.); igor_doubenko@yahoo.com (I.D.); \\ dmazumdar@siu.edu (D.M.); nali@physics.siu.edu (N.A.) \\ 2 Department of Physics \& Astronomy, Louisiana State University, Baton Rouge, LA 70803, USA; \\ stadler@phys.lsu.edu \\ * Correspondence: sudip@siu.edu; Tel.: +1-618-303-8327 \\ Academic Editor: Adriana Greco \\ Received: 5 December 2016; Accepted: 28 December 2016; Published: 5 January 2017
}

\begin{abstract}
The magnetostructural transitions, magnetocaloric effects, and magnetoresistance properties of $\mathrm{Ni}_{45} \mathrm{Mn}_{43} \mathrm{CrSn}_{11}$ Heusler alloys were investigated using X-ray diffraction (XRD), field-dependent magnetization, and electrical resistivity measurements. A large inverse and direct magnetocaloric effect has been observed in $\mathrm{Ni}_{45} \mathrm{Mn}_{43} \mathrm{CrSn}_{11}$ across the martensitic and Curie transition temperature, respectively. The values of the latent heat $(L=15.5 \mathrm{~J} / \mathrm{g})$ and corresponding magnetic $\left(\Delta S_{\mathrm{M}}\right)$ and total $\left(\Delta S_{T}\right)$ entropy changes $\left(\Delta S_{\mathrm{M}}=35 \mathrm{~J} / \mathrm{kg} \cdot \mathrm{K}\right.$ for $\Delta H=5 \mathrm{~T}$ and $\left.\Delta S_{T}=39.7 \mathrm{~J} / \mathrm{kg} \cdot \mathrm{K}\right)$ have been evaluated using magnetic and differential scanning calorimetry (DSC) measurements, respectively. A substantial jump in resistivity was observed across the martensitic transformation. A large negative magnetoresistance $(\sim 67 \%)$ was obtained at the magnetostructural transition for a field change of $5 \mathrm{~T}$. The roles of the magnetic and structural changes on the transition temperatures and the potential application of $\mathrm{Ni}_{45} \mathrm{Mn}_{43} \mathrm{CrSn}_{11}$ Heusler alloys for refrigerator technology are discussed.
\end{abstract}

Keywords: magnetocaloric effects; magnetoresistance; Heusler alloys

\section{Introduction}

Magnetic materials with large magnetic entropy changes $\left(\Delta S_{M}\right)$ are potential candidates for use in new refrigerator technology [1]. Large $\Delta S_{\mathrm{M}}$ values have been observed for a materials showing first order transitions (FOT) in which sharp changes of magnetization occur across the ordering temperature with simultaneous changes in magnetic and structural phases [2,3]. These materials are characterized by a sharp peak in $\Delta S_{\mathrm{M}}$ in a relatively narrow temperature range. In contrast, materials undergoing second order transitions (SOT) exhibit relatively small values of $\Delta S_{\mathrm{M}}$ over wide working temperature intervals [4,5]. The advantage of using materials with a large $\Delta S_{\mathrm{M}}$ at the SOT is the complete reversibility of the magnetization process. Magnetic refrigerant materials that exhibit both magnetic entropy changes can be used in a refrigeration cycle that exploits both effects [6,7].

Much research has been focused on Ni-Mn-based Heusler alloys in order to find compositions in which the martensitic transformations occur around room temperature [8-15]. It has been shown that the substitution of $\mathrm{Co}, \mathrm{Cu}$, and $\mathrm{Al}$ in Ni-Mn-Sn Heusler alloys results in large magnetocaloric effects due to the sudden changes of magnetization and resistance near the martensitic transition temperature [16-18]. Recently, it was reported that the working temperature of the Ni-Mn-Sn Heusler alloys can be controlled by changing the Sn concentration, making them perfect materials for application in magnetic refrigeration [19]. Sutou et al. observed a large magnetic-field-induced strain in Ni-Mn-based Heusler alloys, and discussed the possible application of these alloys for 
Ga-free ferromagnetic shape memory alloys [20]. The magnetic order, magnetocaloric effects, and magnetoresistance in Ni-Mn-Sn Heusler alloys were found to depend on the composition and fabrication conditions. Hence, systematic study of these alloys is still needed.

The main objective of this research is to explore magnetocaloric materials based on Mn-based Heusler alloys, and specifically to understand the properties of magnetic and structural transitions in $\mathrm{Ni}-\mathrm{Mn}-\mathrm{Sn}$. In this paper, we investigate the magnetic, structural, magnetocaloric, thermomagnetic, and magnetoresistance properties of $\mathrm{Ni}_{45} \mathrm{Mn}_{43} \mathrm{CrSn}_{11}$ Heusler alloys through $\mathrm{X}$-ray diffraction, differential scanning calorimetry, magnetization, and resistivity measurements.

\section{Results and Discussion}

The XRD pattern for $\mathrm{Ni}_{45} \mathrm{Mn}_{43} \mathrm{CrSn}_{11}$ at room temperature (Figure 1) indicates that the sample was in mixed martensitic and austenitic phases. The austenitic phase is in a cubic structure and dominates at room temperature, whereas in the martensitic phase, the system is in a tetragonal crystalline state. The XRD peaks from the martensitic phase were characterized by a low intensity, about $30 \%$ of the relative intensity of the austenitic phase.

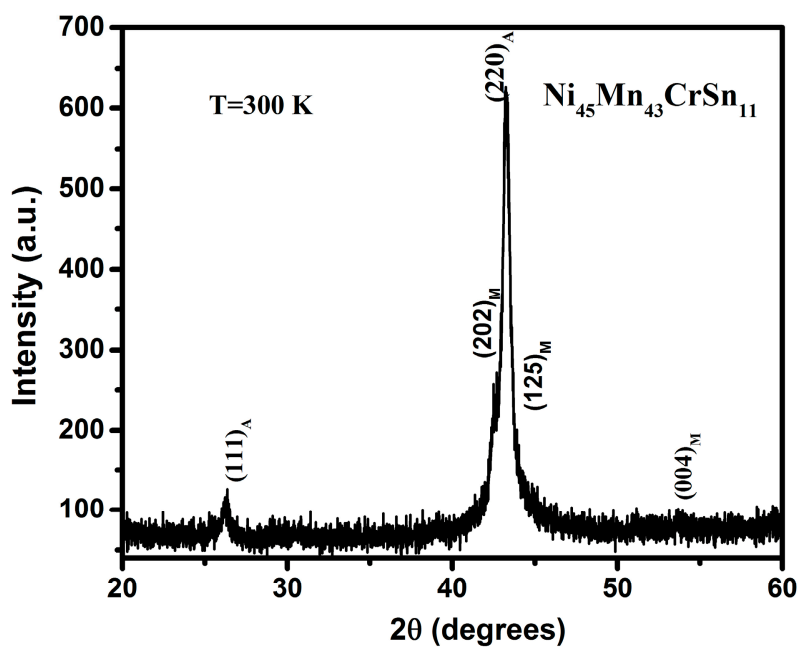

Figure 1. The XRD patterns of $\mathrm{Ni}_{45} \mathrm{Mn}_{43} \mathrm{CrSn}_{11}$ at room temperature. The indexes $(h k l)$ for the martensitic and austenitic phases are represented by $\mathrm{M}$ and $\mathrm{A}$, respectively.

Figure 2a shows the zero-field-cooled (ZFC) and field-cooled (FC) $M(T)$ curves for $\mathrm{Ni}_{45} \mathrm{Mn}_{43} \mathrm{CrSn}_{11}$ in a magnetic field of $100 \mathrm{Oe}$. In the ZFC case, the sample was initially cooled to $5 \mathrm{~K}$ in zero magnetic field, and then data were taken in 100 Oe magnetic field as the temperature increased from $5 \mathrm{~K}$. In FC mode, data were collected during cooling in a field of 100 Oe. The $M(T)$ data show that the sample undergoes three transitions (i) at the Curie temperature of the martensitic phase $\left(T_{\mathrm{CM}}\right.$ ); (ii) at the martensitic transition temperature $\left(T_{\mathrm{M}}\right)$ from a low magnetic state to the FM austenitic phase; and (iii) at the Curie temperature $\left(T_{C}\right)$ from the FM austenitic to the PM austenitic phase. The sample shows a thermal hysteresis in magnetization about $T_{\mathrm{M}}$. The presence of hysteresis and the jump-like change in magnetization at $T_{\mathrm{M}}$ are typical for first-order structural (martensitic) transitions observed in such systems [21]. There is splitting in the ZFC and FC magnetization curves below the blocking temperature $\left(\mathrm{T}_{\mathrm{B}}\right)$. Similar ZFC-FC splitting has been observed in References $[9,22]$, which is attributed to exchange bias phenomena. The high field $(H=5 \mathrm{~T}) \mathrm{ZFC} M(T)$ curves are shown in Figure $2 \mathrm{~b}$. A larger difference in the magnetization of about $30 \mathrm{emu} / \mathrm{g}$ was observed during the cooling at $T=235 \mathrm{~K}$ for $H=5 \mathrm{~T}$ (Figure 2b). Additionally, the shift in temperature $(\Delta T)$ was around $20 \mathrm{~K}$ at $H=5 \mathrm{~T}$ due to the observed field-induced transition [21]. 

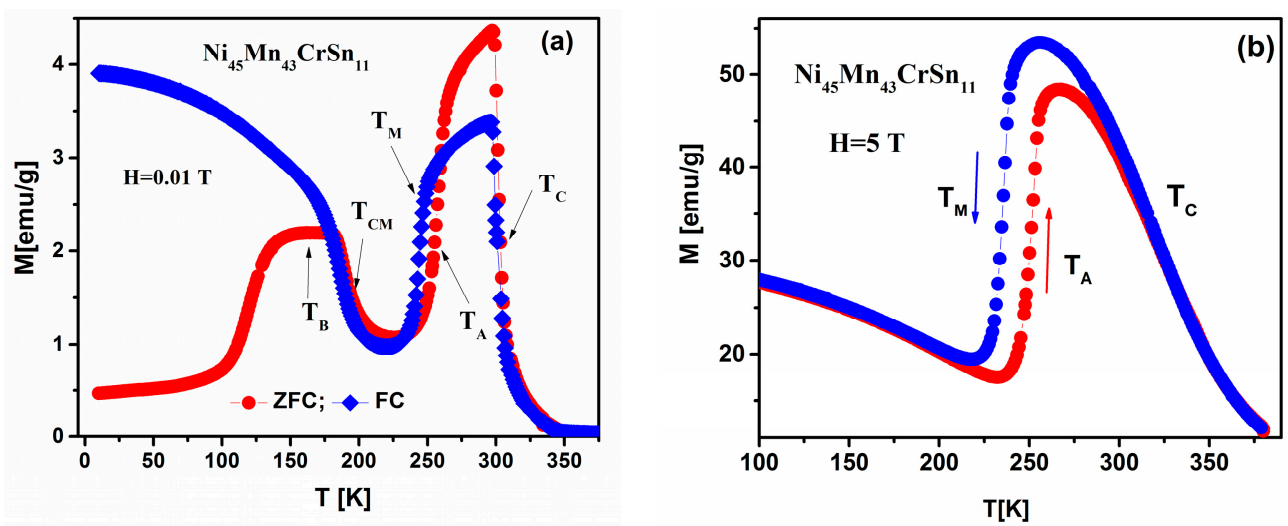

Figure 2. Zero-field-cooled (ZFC) and field-cooled (FC) magnetization $(M)$ vs. temperature $(T)$ curves for $\mathrm{Ni}_{45} \mathrm{Mn}_{43} \mathrm{CrSn}_{11}$ for applied magnetic fields (a) $H=0.01 \mathrm{~T}$ and (b) $H=5 \mathrm{~T}$.

The thermal properties of $\mathrm{Ni}_{45} \mathrm{Mn}_{43} \mathrm{CrSn}_{11}$ were investigate by DSC measurements and are shown in Figure 3. The first-order nature of the phase transitions in $\mathrm{Ni}_{45} \mathrm{Mn}_{43} \mathrm{CrSn}_{11}$ was confirmed by the temperature hysteresis of the heat flow transition peaks (see Figure 3). The large endothermic/exothermic peaks observed during heating/cooling cycles are related to the latent heat of the first-order magnetostructural transition (MST) from the low magnetization martensitic state to the ferromagnetic state. The temperature hysteresis of the heat flow of about $18 \mathrm{~K}$ between heating and cooling cycles detected from DSC measurements is consistent with magnetization results. The latent heat $(L)$ was calculated from the endothermic peak using the relation:

$$
L=\int_{T_{s}}^{T_{f}} \frac{\mathrm{d} Q}{\mathrm{~d} T} \mathrm{~d} T
$$

where $\mathrm{d} Q / \mathrm{d} T$ is the rate of change of heat flow with temperature, and $T_{S}$ and $T_{f}$ are the initial and final temperatures of the magnetostructural phase transitions on heating, respectively. The latent heat of the magnetostructural phase transition and corresponding total entropy changes $\left(\Delta S_{T}\right)$ estimated from DSC curves were $15.5 \mathrm{~J} / \mathrm{g}$ and $39.7 \mathrm{~J} / \mathrm{kg} \cdot \mathrm{K}$, respectively.

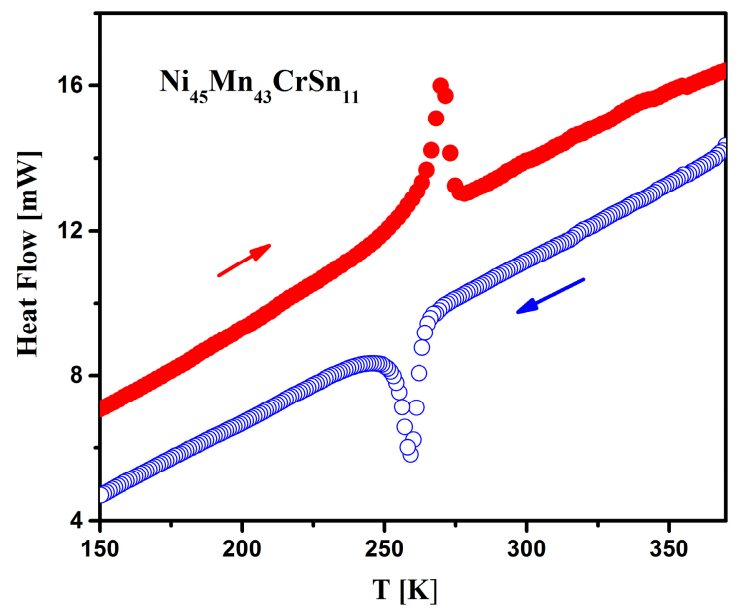

Figure 3. Differential scanning calorimetry (DSC) heat flow curves as a function of temperature for $\mathrm{Ni}_{45} \mathrm{Mn}_{43} \mathrm{CrSn}_{11}$ obtained during cooling (open symbols) and heating (closed symbols).

Isothermal magnetization $M(H)$ curves for the $\mathrm{Ni}_{45} \mathrm{Mn}_{43} \mathrm{CrSn}_{11}$ at $T_{\mathrm{M}}$ and $T_{\mathrm{C}}$ are shown in Figure 4. The metamagnetic-like behavior was observed in the magnetization curves at $T_{M}$ due to a field-induced transition. The magnetic susceptibility of the sample calculated from the results shown in 
Figure 2 demonstrates a Curie-Weiss behavior that is characteristic of a parametric phase for $T>318 \mathrm{~K}$. In the low magnetic field region, the initial susceptibility increases drastically with temperature starting at $305 \mathrm{~K}$.

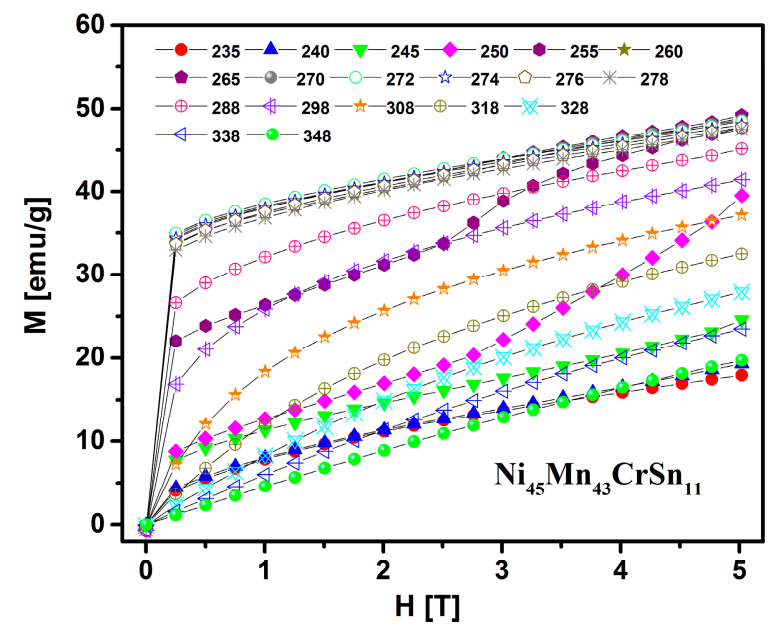

Figure 4. Magnetization isotherms of $\mathrm{Ni}_{45} \mathrm{Mn}_{43} \mathrm{CrSn}_{11}$ at $T_{\mathrm{M}}$ and $T_{\mathrm{C}}$.

The magnetic entropy changes $\left(\Delta S_{\mathrm{M}}\right)$ were estimated from the magnetization isotherms measured at different temperatures calculated using the Maxwell relation from [23]. It has been calculated that the entropy changes estimated by the Clausis-Clapeyron equation and Maxwell's relation are in good agreement in the case of Mn-based Heusler alloys [6]. Figure 5 shows the $\Delta S_{\mathrm{M}}$ as a function of temperature for various magnetic fields $(\Delta H)$ for $\mathrm{Ni}_{45} \mathrm{Mn}_{43} \mathrm{CrSn} \mathrm{n}_{11}$. The sample exhibits an inverse magnetocaloric effect with $\Delta S_{\mathrm{M}}=+34 \mathrm{~J} / \mathrm{kg} \cdot \mathrm{K}$ at the MST $\left(T_{\mathrm{M}}\right)$ for a magnetic field change of $5 \mathrm{~T}$. These values of $\Delta S_{\mathrm{M}}$ are much larger than those reported in Ni-Mn-Sn based Heusler alloys $(17 \mathrm{~J} / \mathrm{kg} \cdot \mathrm{K})[17,18]$. This large value of $\Delta S_{\mathrm{M}}$ was due to a large $\Delta M$ (as seen in Figure $2 \mathrm{~b}$ ). Additionally, the entropy change associated with the magnetic transition is over a relatively wider range of temperature, even though the values are comparatively smaller $(\sim 6.5 \mathrm{~J} / \mathrm{kg} \cdot \mathrm{K})$. From the inset of Figure 5, one can see that the $\Delta S_{\mathrm{M}}$ increases almost linearly with $\Delta H$ at $T_{\mathrm{M}}$ and $T_{\mathrm{C}}$.

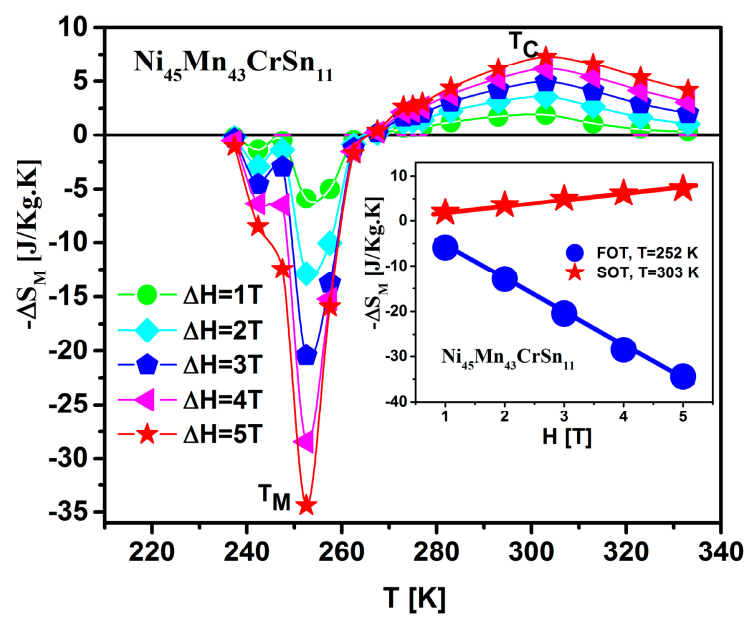

Figure 5. Magnetic entropy changes $\left(\Delta S_{M}\right)$ as a function of temperature for $\mathrm{Ni}_{45} \mathrm{Mn}_{43} \mathrm{CrSn}_{11}$ for a magnetic field change $(\Delta H)$ of $5 \mathrm{~T}$. The inset shows $\Delta S_{\mathrm{M}}$ as a function of applied magnetic field. FOT: first order transition; SOT: second order transition. 
The refrigeration capacity $(\mathrm{RC})$ is another useful parameter used to quantify MCE properties. It has been calculated by integrating the $\Delta S_{M}(T, H)$ curve over the full width at half maximum using the relation [23]:

$$
\mathrm{RC}=\int_{T_{1}}^{T_{2}} \Delta S_{M}(T) \mathrm{d} T
$$

The maximum RC values for $\mathrm{Ni}_{45} \mathrm{Mn}_{43} \mathrm{CrSn}_{11}$ was $380 \mathrm{~J} / \mathrm{kg}$ and $220 \mathrm{~J} / \mathrm{kg}$ at the SOT and FOT, respectively, for a magnetic field change of $5 \mathrm{~T}$. These $\mathrm{RC}$ values are comparable to those observed in Ni-Mn-Sn systems near room temperature [16]. Since magnetic and thermal hysteresis have been observed at the FOT—which are disadvantageous for magnetic refrigeration-the magnetocaloric properties at SOTs are more favorable for refrigeration.

The ZFC resistivity $\rho(T)$ curves of $\mathrm{Ni}_{45} \mathrm{Mn}_{43} \mathrm{CrSn}_{11}$ at magnetic fields of 0 and $5 \mathrm{~T}$ are shown in Figure 6a. At low temperature, the resistivity curves remain relatively constant until the step-like drops in the resistivity were observed in the vicinity of $T_{M}$ (see Figure 6a). The large jump near $T_{M}$ is due to a metamagnetic transition from a low magnetization state with strong antiferromagnetic correlations to a ferromagnetic austenitic phase. The application of a magnetic field shifts the jump in resistivity toward lower temperatures, resulting in the giant MR. The maximum MR was found to be $\sim-67 \%$ at $T \approx 251 \mathrm{~K}$ when the system passes from the low magnetization state of the martensitic phase to the ferromagnetic austenitic phase (see Figure $6 \mathrm{~b}$ ). The observed MR value for $\mathrm{Ni}_{45} \mathrm{Mn}_{43} \mathrm{CrSn}_{11}$ is $20 \%$ larger than those reported for Sn-based Heusler alloys [16], and similar to those observed in $\mathrm{Ni}_{50} \mathrm{Mn}_{34} \mathrm{In}_{16}$ Heusler alloys [12].
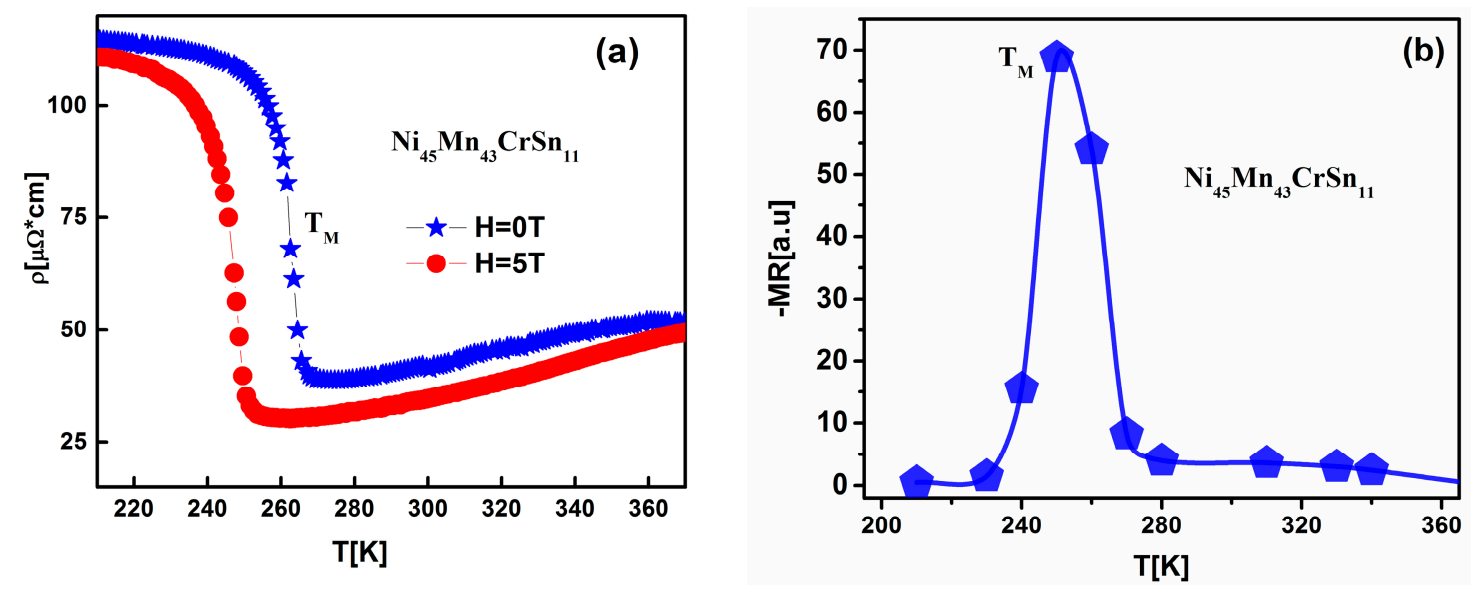

Figure 6. (a)Temperature dependence of the resistivity for $\mathrm{Ni}_{45} \mathrm{Mn}_{43} \mathrm{CrSn}_{11}$ at $H=0 \mathrm{~T}$ (stars), and at $H=5 \mathrm{~T}$ (circles); (b)The magnetoresistance (MR) as a function of temperature calculated from $\rho(T, H)$ curves for $\Delta H=5 \mathrm{~T}$.

\section{Materials and Methods}

A stoichiometric polycrystalline ingot ( $3 \mathrm{~g}$ ) of $\mathrm{Ni}_{45} \mathrm{Mn}_{43} \mathrm{CrSn}_{11}$ was fabricated by conventional arc-melting in an ultra-high purity argon atmosphere using high-purity (Ni: 99.9\%; Mn, Cr: 99.99\%; and Sn: $99.9999 \%$ ) elements. For homogenization, the sample was wrapped in tantalum foil and annealed at $1123 \mathrm{~K}$ for $24 \mathrm{~h}$ in high vacuum $\left(\approx 10^{-4}\right.$ torr) and slowly cooled to room temperature. X-ray diffraction (XRD) measurements were done with an X-ray diffractometer (GMC-Mini Materials Analyzer, Hampshire, IL, USA) using $\mathrm{Cu}-\mathrm{K} \alpha$ radiation to determine the phase purity and crystal structure. The magnetic properties were measured in a temperature interval of 5-400 K, and in magnetic fields up to $5 \mathrm{~T}$, using a superconducting quantum interference device (SQUID) magnetometer by Quantum Design, Inc., San Diego, CA, USA. The resistance and magnetoresistance (MR) of the sample was studied using the four probe method within the temperature interval of $5-400 \mathrm{~K}$ and in magnetic fields up to $5 \mathrm{~T}$. All magnetotransport measurements were carried out in zero-field-cooled (ZFC) 
conditions. The $\mathrm{MR}(H, T)$ values were calculated using $\mathrm{MR}=[\{R(H, T)-R(0, T)\} / R(0, T)] \times 100 \%$. The differential scanning calorimetry (DSC) measurements were carried out employing a Perkin-Elmer DSC 8000 instrument (with the ramp rate of $20 \mathrm{~K} / \mathrm{min}$ during heating and cooling) (PerkinElmer, Santa Clara, CA, USA) in the temperature range 123-473 K.

\section{Conclusions}

We have investigated the magnetic, structural, thermal, transport, and magnetocaloric properties of $\mathrm{Ni}_{45} \mathrm{Mn}_{43} \mathrm{CrSn}_{11}$ alloys. This compound exhibits large inverse and direct magnetocaloric effects of $35 \mathrm{~J} / \mathrm{kg} \cdot \mathrm{K}$ and $6.5 \mathrm{~J} / \mathrm{kg} \cdot \mathrm{K}$ at $T_{\mathrm{M}}$ and $T_{\mathrm{C}}$, respectively. The application of a magnetic field shifts the jump in resistivity towards lower temperatures, resulting in a giant MR $(\sim-67 \%)$. The maximum $\mathrm{RC}$ values for a magnetic field change of $5 \mathrm{~T}$ were found to be $380 \mathrm{~J} / \mathrm{kg}$ and $220 \mathrm{~J} / \mathrm{kg}$ at the SOT and FOT, respectively. The large magnetocaloric effect, magnetoresistance, and relatively low cost of the constituents of the Ni-Mn-Cr-Sn alloys make these compounds potential working materials for magnetic refrigeration.

Acknowledgments: This work was supported by the Office of Basic Energy Sciences, Material Science Division of the U.S. Department of Energy, DOE Grant No. DE-FG02-06ER46291 (SIU) and DE-FG02-13ER46946 (LSU).

Author Contributions: Naushad Ali, Shane Stadler, Dipanjan Mazumdar, Igor Dubenko, and Sudip Pandey gather the ideas and make a plan to do the experiments. Sudip Pandey, Anil Aryal and Abdiel Quetz performed the experiments. Data analysis is done by Sudip Pandey. All the authors contributed to the discussions. Sudip Pandey wrote the manuscript.

Conflicts of Interest: The authors declare no conflict of interest.

\section{References}

1. Glanz, J. Making a bigger chill with magnets. Science 1998, 279, 2045. [CrossRef]

2. Tegus, O.; Bruck, E.; Buschow, K.H.; de Boer, F.R. Transition-metal-based magnetic refrigerants for room-temperature applications. Nature (London) 2002, 415, 150-152. [CrossRef] [PubMed]

3. Provenzano, V.; Shapiro, A.J.; Shull, R.D. Reduction of hysteresis losses in the magnetic refrigerant $\mathrm{Gd}_{5} \mathrm{Ge}_{2} \mathrm{Si}_{2}$ by the addition of iron. Nature (London) 2004, 429, 853-857. [CrossRef] [PubMed]

4. Brown, G.V. Magnetic heat pumping near room temperature. J. Appl. Phys. Lett. 1976, 47, 3673-3680. [CrossRef]

5. Mazet, T.; Thou-Mouko, H.; Malam, B. $\mathrm{Mn}_{3} \mathrm{Sn}$ : A promising material for magnetic refrigeration. Appl. Phys. Lett. 2006, 89, 0222503. [CrossRef]

6. Zhang, X.; Zhang, B.; Yu, S.; Liu, Z.; Xu, W.; Liu, G.; Chen, J.; Cao, Z.; Wu, G. Combined giant inverse and normal magnetocaloric effect for room-temperature magnetic cooling. Phys. Rev. B 2007, 76, 132403. [CrossRef]

7. Moya, X.; Mañosa, L.; Planes, A.; Aksoy, S.; Acet, M.; Wassermann, E.F.; Krenke, T. Cooling and heating by adiabatic magnetization in the Ni50Mn34In16 magnetic shape-memory alloy. Phys. Rev. B 2007, 75, 184412. [CrossRef]

8. Pandey, S.; Quetz, A.; Aryal, A.; Samanta, T.; Dubenko, I.; Stadler, S.; Ali, N. Magnetic, transport, and magnetocaloric properties of boron doped Ni-Mn-In alloys. J. Appl. Phys. 2015, 117, 183905. [CrossRef]

9. Pathak, A.K.; Khan, M.; Gautam, B.R.; Stadler, S.; Dubenko, I.; Ali, N. Exchange bias in bulk Ni-Mn-In-based Heusler alloys. J. Magn. Magn. Mat. 2009, 321, 963-965. [CrossRef]

10. Dubenko, I.; Khan, M.; Pathak, A.K.; Gautam, B.R.; Stadler, S.; Ali, N. Magnetocaloric effects in Ni-Mn-X based Heusler alloys with $X=\mathrm{Ga}$, Sb, In. J. Magn. Magn. Mat. 2009, 321, 754-757. [CrossRef]

11. Khan, M.; Pathak, A.K.; Paudel, M.R.; Dubenko, I.; Stadler, S.; Ali, N. Magnetoresistance and field-induced structural transitions in $\mathrm{Ni}_{50} \mathrm{Mn}_{50-x} \mathrm{Sn}_{x}$ Heusler alloys. J. Magn. Magn. Mater. 2008, 320, L21. [CrossRef]

12. Yu, S.Y.; Liu, Z.H.; Liu, G.D.; Chen, J.L.; Cao, Z.X.; Wu, G.H.; Zhang, B.; Zhang, X.X. Large magnetoresistance in single-crystalline $\mathrm{Ni}_{50} \mathrm{Mn}_{50-x} \mathrm{In}_{x}$ alloys $(x=14-16)$ upon martensitic transformation. Appl. Phys. Lett. 2006, 89, 162503. [CrossRef] 
13. Pandey, S.; Quetz, A.; Aryal, A.; Samanta, T.; Dubenko, I.; Stadler, S.; Ali, N. The effects of substituting Ag for In on the magnetoresistance and magnetocaloric properties of Ni-Mn-In Heusler alloys. AIP Adv. 2016, 6, 056213. [CrossRef]

14. Dubenko, I.; Quetz, A.; Pandey, S.; Aryal, A.; Eubank, M.; Rodionov, I.; Prudnikov, V.; Granovsky, A.; Lahderanta, E.; Samanta, T.; et al. Multifunctional properties related to magnetostructural transitions in ternary and quaternary Heusler alloys. J. Magn. Magn. Mater. 2015, 383, 186-189. [CrossRef]

15. Quetz, A.; Koshkidko, Y.; Titov, I.; Rodionov, I.; Pandey, S.; Aryal, A.; Ibarra-Gaytan, P.J.; Prudnikov, V.; Granovsky, A.; Dubenko, I.; et al. Giant reversible inverse magnetocaloric effects in $\mathrm{Ni}_{50} \mathrm{Mn}_{35} \mathrm{In}_{15}$ Heusler alloys. J. Alloy. Compd. 2016, 683, 139-142. [CrossRef]

16. Han, Z.; Wang, D.H.; Qian, B.; Feng, J.; Jiang, X.; Du, Y. Phase transitions, magnetocaloric effect and magnetoresistance in Ni-Co-Mn-Sn ferromagnetic shape memory alloy. Jpn. J. Appl. Phys. 2010, 49, 0211. [CrossRef]

17. Wang, D.H.; Zhang, C.L.; Xuan, H.C.; Han, Z.D.; Zhang, J.R.; Tang, S.L.; Gu, B.X.; Du, Y.W. The study of low-field positive and negative magnetic entropy changes in $\mathrm{Ni}_{43} \mathrm{Mn}_{46-x} \mathrm{Cu}_{x} \mathrm{Sn}_{11}$ alloys. J. Appl. Phys. 2007, 102, 013909. [CrossRef]

18. Chen, X.; Naik, V.B.; Mahendiran, R.; Ramanujan, R.V. Optimization of Ni-Co-Mn-Sn Heusler alloy composition for near room temperature magnetic cooling. J. Alloy. Compd. 2016, 618, 187-191. [CrossRef]

19. Dan, N.H.; Duc, N.H.; Yen, N.H.; Thanh, P.T.; Bau, L.V.; Bang, N.A.; Mai, N.T.; Anh, P.K.; Thanh, T.D.; Phan, T.L.; et al. Magnetic properties and magnetocaloric effect in Ni-Mn-Sn alloys. J. Magn. Magn. Mater. 2015, 374, 372-375. [CrossRef]

20. Sutou, Y.V.; Imano, Y.; Koeda, N.; Omori, T.; Kainuma, R.; Ishida, K.; Olikawa, K. Magnetic and martensitic transformations of $\mathrm{NiMnX}(X=\mathrm{In}, \mathrm{Sn}, \mathrm{Sb})$ ferromagnetic shape memory alloys. Appl. Phys. Lett. 2004, 85, 4358-4360. [CrossRef]

21. Krenke, T.; Duman, E.; Acet, M.; Wassermann, E.F.; Moya, X.; Mañosa, L.; Planes, A.; Suard, E.; Ouladdiaf, B. Magnetic super elasticity and inverse magnetocaloric effect in NiMnIn. Phys. Rev. B 2007, 75, 104414. [CrossRef]

22. Khan, M.; Dubenko, I.; Stadler, S.; Ali, N. Exchange bias in bulk Mn rich Ni-Mn-Sn Heusler alloys. J. Appl. Phys. 2007, 102, 113914. [CrossRef]

23. Tishin, A.M.; Spichkin, Y.I. The Magnetocaloric Effects and Its Applications; IOP Publishing Ltd: Bristol, UK, 2003.

(C) 2017 by the authors; licensee MDPI, Basel, Switzerland. This article is an open access article distributed under the terms and conditions of the Creative Commons Attribution (CC-BY) license (http://creativecommons.org/licenses/by/4.0/). 